\title{
Profound hypotension after the first dose of ketanserin
}

\author{
P.C. Waller, ${ }^{*}$ H.A. Cameron, $\dagger$ and L.E. Ramsay \\ University Department of Therapeutics, Royal Hallamshire Hospital, Sheffield S10 2JF, UK.
}

\begin{abstract}
Summary: Two patients developed profound hypotension approximately one hour after taking an initial oral dose of ketanserin $\mathbf{4 0} \mathrm{mg}$. The reaction appeared similar to that reported with prazosin, and may have been due to the $\alpha_{1}$-adrenoceptor antagonist action of ketanserin. Both patients were taking regular $\beta$-blocker therapy, which may exacerbate such a reaction.
\end{abstract}

\section{Introduction}

Ketanserin is a selective antagonist at 5-hydroxytryptamine $2\left(S_{2}\right)$ receptors which also has $\alpha_{1}$-adrenoceptor antagonist activity. In hypertensive patients it lowers blood pressure with no significant orthostatic effect. ${ }^{1}$ The relative roles of $S_{2}$ and $\alpha_{1}$-adrenoceptor antagonism in its antihypertensive action in man are uncertain. ${ }^{2,3}$ Alpha 1 -adrenoceptor antagonists such as prazosin occasionally cause a first dose reaction, ${ }^{4}$ due to an unpredictably large fall in standing blood pressure. This phenomenon was not observed in one study of 21 hypertensive patients who were given doses of 20 or $40 \mathrm{mg}$ ketanserin. ${ }^{5}$ However, marked symptomatic hypotension has been reported after a $10 \mathrm{mg}$ intravenous injection of ketanserin ${ }^{6}$ and after $60 \mathrm{mg}$ oral dosage. ${ }^{7}$ We report severe hypotensive reactions in two patients following treatment with a first dose of ketanserin $40 \mathrm{mg}$. Both patients had consented in writing to participate in formal studies which had been approved by the hospital ethics commitee.

\section{Case reports}

Case 1

A 65 year old woman with a 14 year history of hypertension, but no evidence of ischaemic heart disease, had been treated with atenolol $100 \mathrm{mg}$ and bendrofluazide $5 \mathrm{mg}$ daily, and had taken these drugs

Correspondence: L.E. Ramsay, F.R.C.P.

*Present address: Glasgow Blood Pressure Clinic, Western Infirmary, Glasgow G11 6NT.

'Present address: I.C.I. Pharmaceuticals Division, Mereside, Alderley Park, Macclesfield, Cheshire, SK10 4TG.

Accepted: 5 November 1986 on the day of the reaction. During a study investigating the pharmacokinetics of ketanserin in hypertensive patients she was given ketanserin $\mathbf{4 0} \mathrm{mg}$ orally after an overnight fast, and was observed supine in the laboratory. Blood pressure and heart rate were measured by a Dinamap 845 semi-automated recorder. Before taking ketanserin her blood pressure was $154 / 96 \mathrm{~mm} \mathrm{Hg}$ and heart rate $66 /$ minute. After 50 minutes she became pale, nauseated and faint. Although she remained supine she lost consciousness briefly, but recovered before any action was required. Blood pressure had fallen to $74 / 50 \mathrm{~mm} \mathrm{Hg}$ and she had a bradycardia of 43/minute (Figure 1). Electrocardiographic monitoring showed no arrhythmia and

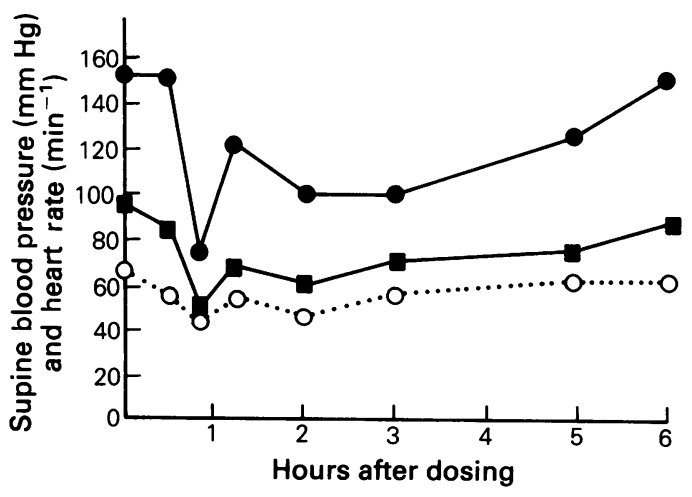

Figure 1 Effect of $40 \mathrm{mg}$ single dose of ketanserin on blood pressure and heart-rate (Case 1). systolic blood pressure; $\square-\square$, diastolic blood pressure; $\bigcirc$.......... O, heart-rate.

(C) The Fellowship of Postgraduate Medicine, 1987 
serial 12-lead electrocardiograms showed no abnormality. Twenty minutes after the syncopal episode her blood pressure had risen to $120 / 68 \mathrm{~mm} \mathrm{Hg}$ and she felt better. However, nausea and drowsiness persisted for 6 hours, after which she recovered completely.

\section{Case 2}

A normotensive 62 year old man had a 15 month history of chronic stable angina, but no evidence of previous myocardial infarction. His usual treatment was atenolol $100 \mathrm{mg}$ daily and isosorbide dinitrate $5 \mathrm{mg}$ b.d., and he had taken both drugs on the morning of the reaction. He continued to experience angina despite this treatment, and entered a study designed to examine the anti-anginal effect of ketanserin when added to beta-blocker therapy. ${ }^{8} \mathrm{He}$ received $40 \mathrm{mg}$ ketanserin orally after an overnight fast. Prior to this his standing blood pressure was $118 / 84 \mathrm{~mm} \mathrm{Hg}$ and heart rate 70/minute. After 50 minutes he complained of dizziness and was noted to be pale. Standing blood pressure had fallen to $60 / 0 \mathrm{~mm} \mathrm{Hg}$ and his heart rate was $43 /$ minute. After resting in the supine position for 20 minutes his blood pressure had recovered to 114/ $70 \mathrm{~mm} \mathrm{Hg}$. He became drowsy and slept for 2 hours, and then felt completely well. Electrocardiographic monitoring and 12-lead electrocardiograms showed no arrhythmias or acute ischaemia.

\section{Discussion}

The reactions to the first dose of ketanserin experienced by these two patients were very similar as regards time of onset ( 50 minutes), the occurrence of profound hypotension and bradycardia, and the presence of persistent drowsiness. The onset of the reaction coincided with the time that the plasma ketanserin concentration usually reaches its peak. ${ }^{9}$ We have observed a

\section{References}

1. Cameron, H.A. \& Ramsay, L.E. Ketanserin in essential hypertension: a double-blind placebo-controlled study. Postgrad Med J 1985, 61: 583-586.

2. Reimann, I.W. \& Frohlich, J.C. Mechanism of antihypertensive action of ketanserin in man. Br Med J 1983, 287: 381-383.

3. Wenting, G.J., Woittiez, A.J.J., Man in 't Veld, A.J. \& Schalekamp, M.A.D.H. 5-HT, alpha-adrenoceptors and blood pressure: effects of ketanserin in essential hypertension and autonomic insufficiency. Hypertension 1984, 6: $100-109$.

4. Bendall, M.J., Baloch, K.H. \& Wilson, P.R. Side-effects due to treatment of hypertension with prazosin. $\mathrm{Br}$ Med $J$ 1975, ii, 727-728.

5. Hosie, J. \& Gould, S. Does ketanserin have a first dose similar reaction in a third patient after a first dose of $40 \mathrm{mg}$ ketanserin, but blood pressure was no measured during the episode.

These reactions appear very similar to those repor $\stackrel{C}{-}$ ted after the first dose of prazosin and may be relate $\vec{F}$ to the $\alpha_{1}$-antagonist activity of ketanserin. Prazosin reactions are usually preceded by a slowing of the heart rate, and the ability to maintain a reflex tachycardia may be important in preventing syncope..$_{\mathbb{D}}^{10}$ The patients we describe were both taking atenolof and it is known that concomitant administration of $\mathfrak{a}^{\circ}$ $\beta$-adrenoceptor antagonist reduces this reflex res $\overrightarrow{0}$ ponse. ${ }^{11}$ Prazosin reactions are generally more severe in patients pre-treated with a $\beta$-blocker. ${ }^{12}$

Hosie \& Gould ${ }^{5}$ did not observe any first dosec reaction in 21 patients given an initial dose of $40 \mathrm{mg}$ ketanserin. However, the $95 \%$ confidence limit for anobserved incidence of $0 / 21$ is $14 \%,{ }^{13}$ so this problem could be quite common despite the negative finding. It also should be noted that their patients were given $\eta_{\omega}^{\infty}$ ketanserin alone. Other workers have observed severe् hypotension following intravenous ketanserin $10 \mathrm{mg}$ and in two of 10 patients given a $60 \mathrm{mg}$ oral dose. ${ }^{7} \mathrm{We}_{\text {- }}$ have not observed this reaction in 51 patients whos started ketanserin at a dose of $20 \mathrm{mg}$. This does no? exclude the possibility of initial reactions to this dose The true incidence could be as high as $6 \%$, which is $95 \%$ confidence limit for an observation of $0 / 51 .{ }^{13} \mathrm{e}^{\mathrm{V}}$ suggest that initial doses of ketanserin higher than $20 \mathrm{mg}$ should be avoided, and that the suitability ofas $20 \mathrm{mg}$ starting dose should be examined in a large population of patients, particularly those treated witho a $\beta$-blocker.

\section{Acknowledgement}

Financial support for P.C.W. and H.A.C. from Jansseno Pharmaceutical Ltd is gratefully acknowledged.

effect in hypertension? Br J Clin Pharmacol 1985, 20:

6. Wenting, G.J., Man in 't Veld, A.J., Woittiez, A.J., Boomsma, F. \& Schalekamp, M.A.D.H. Treatment of hypertension with ketanserin, a new selective $5-\mathrm{HT}_{2} \mathrm{O}$ receptor antagonist. $\mathrm{Br} \mathrm{Med} J$ 1982, 284: 537-539.

7. Andren, L., Svensson, A., Dahlof, B., Eggertson, R. \&N Hansson, L. Ketanserin in hypertension. Acta Med
Scand 1983, 214: 125-130.

8. Cameron. H.A., Cameron. C.M. \& Ramsay, L.E. Com- $-\frac{O}{C}$ parison of single doses of ketanserin and placebo in chronic stable angina. Br J Clin Pharmacol 1986, 22:? 114-6.

9. Hedner, T., Persson, B. \& Berglund, G. Ketanserin, a novel 5-hydroxytryptamine antagonist: monotherapy in 
essential hypertension. Br J Clin Pharmacol 1983, 16: 121-125.

10. Rubin, P.C. \& Blaschke, T.F. Studies on the clinical pharmacology of prazosin I: Cardiovascular, catecholamine and endocrine changes following a single dose. Br J Clin Pharmacol 1980, 10: 23-32.

11. Elliott, H.L., McLean, K., Sumner, D.J., Meredith, P.A. \& Reid, J.L. Immediate cardiovascular responses to oral prazosin - effects of concurrent $\beta$-blockers. Clin Pharmacol Ther 1981, 29: 303-309.
12. Seideman, P., Grohnen, A., Haglund, K., Lindstrom, B. \& Von Bohr, C. Prazosin first dose phenomenon during combined treatment with a $\beta$-adrenoceptor blocker in hypertensive patients. $\mathrm{Br} J$ Clin Pharmacol 1982, 13: 865-870.

13. Hanley, J.A. \& Lippman-Hand, A. If nothing goes wrong, is everything all right? Interpreting zero numerators. JAMA 1983, 249: 1743-1745. 